\title{
LA CRONOLOGÍA DE LA «HISTORIA WAMBAE»
}

\author{
YolANDA GARCÍ LÓPEZ \\ Universidad de Santiago de Compostela
}

Las interpretaciones globales o los estudios pormenorizados de la Historia Wambae ${ }^{1}$ nunca han problematizado la cronología de este texto ${ }^{2}$; y, sin embargo, nadie ha aportado argumentos de peso para fijar el momento en que Julián redactó su monografía o las piezas menores que la acompañan en la tradición: una invectiva contra la Galia (la Insultatio) que es un desarrollo por separado, muy retórico, de uno de los temas de la Historia, y también formalmente está muy vinculado a ella ${ }^{3}$; y el Iudicium in tyrannorum perfidia promulgatum, cuya relación con los dos escritos anteriores es, como veremos, mucho más problemática.

El relato histórico se inicia con la escena del nombramiento y unción de Wamba (septiembre del a. 672) para ocuparse después íntegramente de unos sucesos acaecidos un año más tarde -septiembre del 673-: el alzamiento en Narbona de un usurpador, el duque Paulo, la expedición bélica de Wamba contra él, su derrota y enjuiciamiento; finalmente la pacificación de la provincia levantisca y la entrada triunfal de Wamba en Toledo. Los estudiosos han leído el retrato «ideal» del monarca legítimo que ofrece la Historia en clave de panegírico, como un alegato "pro Wamba» de carác-

1 Con el segundo calificativo me refiero primordialmente al estudio que incluye Suzanne Terulet en su obra Des Gotbs à la nation gothique, París, 1984 pp. 585-636. Citaré la Historia y escritos adyacentes por la ed. del Corpus Cbrist. Latin. CVX, Turnhout 1976 (reproducción empobrecida de la de Levisson en los M.G.H).

${ }^{2} \mathrm{Y}$ el único que lo ha hecho -Roger Cousns, Julian of Toledo and the Royal Succession in late seventb-century Spain en «Early Medieval Kingship», ed. SAWYBR-WOOD, Leeds, 1977, pp.40-41- era escéptico sobre la posibilidad de llegar a conocer la fecha de escritura de la obra.

${ }^{3}$ El título completo en los mss. (algunos lo omiten) es «Insultatio vilis storici in tyrannidem Galliae»; en el explicit «Insultatio vilis provinciae Galliae». Su unidad con la monografia se afianza si Collins acierta con la fuente que pudo inspirar a Julián la redacción de este complemento (v.art. cit. n. 2 p. 39). 
ter más o menos oficialista, y de ahí se seguía necesariamente una cercanía entre la narración y lo narrado, o por lo menos la escritura de la obra durante el reinado del protagonista -aunque esta segunda opción que podía retrasar la fecha hasta el 680 apenas es tenida en cuenta ${ }^{4}-$

Partiendo de ese supuesto, eran factibles otras especulaciones; una muy fácil y repetida nos dice que Julián -aún simple clérigo- debió ganar con esta pieza el favor de Wamba y tal vez su posterior ascenso a la mitra toledana cuando quedó libre por la muerte de Quírico (en enero del a. 680); otra apunta la posibilidad de que el escrito estuviera destinado a conmemorar «el primer aniversario de la victoria de Wamba, el 1 de septiembre del 674 , que era al mismo tiempo el aniversario de su advenimiento"s.

Aunque esta afirmación tiene más interés pues se razona sobre un sincronismo muy imbricado en la estructura de la propia obra, sigue sustentándose, como todas las dataciones en torno al 673 , en su carácter panegírico, y es éste el que tropieza con dificultades: no encaja el género literario elegido por Julián, ni la distancia que el narrador mantiene frente al presunto homenajeado, sin implicarle en ningún momento afectivamente con un apóstrofe o algún tipo de referencia al presente; como dice Collins -que llamó sin éxito la atención sobre la falta de base de la cronología o el móvil encomiástico atribuidos al escrito-, si la intención era glorificar a Wamba, «it has a most peculiar way of going about it" ${ }^{6}$.

Si el elogio del personaje concreto, Wamba, es un fin discutible, no lo es otra de las orientaciones que habitualmente se le reconocen, la «ejemplarizante»; una y otra vez las acciones se enfocan hacia propuestas abstractas en torno a puntos «calientes" en la ideología política (y creo que también una coyuntura particular) del momento. La seriación histórica (en la que alternan episodios verídicos más o menos idealizados, con otros emblemáticos sin duda) es casi un pretexto para mostrar ejemplos de conducta, en pri-

${ }^{4}$ La menciona de forma marginal E.A.THOMPSON, Los godos en España, Madrid, 1971 p. 249; la coetaneidad es asumida de forma automática por los estudiosos del mundo visigodo (Diesner, Claude, Hillgarth, Teillet, el mismo Thompson, etc.).

s Con el advenimiento comienza la monografía, y en los capítulos finales se resalta la coincidencia de aquella data y la de la derrota de Paulo, formando así un hilo de enlace entre las dos partes argumentales de la obra; las palabras y la tesis son de Teillet, L'Historia Wambae, est-elle une oeuvre de circonstance? «Actas de la Semana Internacional de Estudios Visigóticos (octubre 1985)», Murcia 1987, p. 417.

6 Art.cit. n.2, p. 40. No sé si acierta Tellet en algunas de las razones que alega (art. cit. n. 5, p. 416) para justificar que Julián «evitara» la forma literaria del panegírico, pero aunque envolviera su elogio de Wamba en una monografía histórica epor qué renunciar a hacer más explícito y «personal » ese elogio?: no renunciaron a ello los escritores que cita ella misma en ese lugar por haber elegido para un panegírico formas literarias distintas a la canónica. 
mer término a la monarquía, pero también a otros estamentos (ejército, obispos). Para recalcar la «doctrina», Julián se sirve del procedimiento clásico de contraponer al elogio de Wamba y sus fieles, la condena de las actitudes antitéticas del tyrannus Paulus y los que han seguido su facción.

$Y$ es en ese plan docente donde se da un contraste paradójico que no se ha tenido en cuenta: los principios propuestos coinciden con medidas legislativas que adopta al subir al trono el sucesor de Wamba, Ervigio, bien en el concilio nacional de Toledo XII (enero del 681$)^{7}$ presidido por Julián, y/o en las reformas de las leyes que se realizan ese mismo año en el código civil (el Liber Iudiciorum ${ }^{8}$ ); y, por otro lado, algunas de las doctrinas están reñidas (y esa distancia se acentúa por el paralelismo mencionado) con actuaciones bien documentadas de Wamba. Los lugares donde se cruzan la Historia y las políticas del periodo inicial ervigiano parecen cobrar mucho más sentido si se retrasa la fecha tradicional de la monografía, pero además uno de ellos contiene una indicación cronológica que apunta en el mismo sentido.

Empezaré por ese dato más directo. Su contexto es el proceso contra Paulo y sus socios descrito en el capítulo 27 de la Historia:

... coram exercitibus cunctis adiudicatur cum ceteris, quum universorum iudicio et mortem exciperent qui mortem principi praeparassent. Sed nulla mortis super eos inlata sententia, decaluationis tantum, ut praecipitur, sustinuere uindictam.

La ley contra traidores que teóricamente rige en la época de Wamba es la de Chindasvindo recogida como 2.1.6 en el Liber de Recesvindo; en ella el castigo sustitutorio de la pena capital no es la decalvación que menciona el relato, sino la ceguera:

...si fortasse pietatis intuitu a principe fuerit illi uita concessa, non aliter quam effossis oculis relinquantur ad uitam.. (ZEUMER, p. 55 col.1).

Sólo en la reforma legal de Ervigio (entra en vigor en octubre del 681), esa cláusula será sustituida por una fórmula penal típica de sus leyes, que, entre otras cosas, transforma la ceguera en decalvatio. De esa discordancia entre la pena que según Julián decretó Wamba y la norma supuestamente vigente en el momento de los sucesos no sería lícito extraer consecuencias cronológicas, so pena de caer en planteamientos anacrónicos sobre la aplica-

7 Citaré los textos conciliares por la ed. de J. VIVes, Concilios visigbticos e bispano-romanos, Barcelona-Madrid, 1963.

8 Utilizo la ed. de Karl Zeumer, Leges Visigothorum, M.G.H Legum Sectio I, Hannover, 1902. 
ción efectiva y literal de la ley escrita en esta época, pero es que Julián por medio del paréntesis «ut praecipitur» está subrayando que el recurso a la decalvatio es lo prescrito legalmente en algún lugar que no puede ser otro que la lex regia, el Liber ludiciorum; está entonces amparando la sentencia en la forma renovada de la ley contra los perfidi, una forma que ni la tradición manuscrita ni el estilo autorizan a separar de la edición ervigiana del código"; dentro de él, son precisamente sus textos los que emplean "praecipere" para remitir a otras normas del mismo ${ }^{10}$. Por otra parte, el presente "praecipitur", inserto entre los pasados de la narración, parece desvincularse de ésta y remontarnos hasta el momento de escritura; si Julián escribe en el 681 o más tarde, no estaría incurriendo en anacronismo aunque la imprecisión temporal del inciso tiene que ser intencionada ${ }^{11}$ : se trataría de vincular a Wamba -el mecanismo se repetirá a lo largo de la Historia- con conductas -en este caso con el hecho de guiarse por la (o por determinada) ley escrita- que en realidad se hacen efectivas con su sucesor.

Historiadores que han notado ese desajuste puntual entre Historia y ley vigente, pero no sus consecuencias cronológicas ${ }^{12}$, han interpretado que la actuación judicial de Wamba fue el precedente (no codificado) de lo que luego codificaría Ervigio. Lo cierto es que esas frases sólo tienen conexión con el «personaje» que protagoniza la monografía, no con su correlato real. He aquí la prueba: en la otra fuente julianea del proceso contra Paulo, el Iudicium, la sentencia se apoya en un fragmento de la misma ley 2.1.6 pero siguiendo la versión "previsible», la de Chindasvindo, es decir -por ceñirse al contraste más inmediato - los traidores son en esta versión condenados a la pérdida de los ojos

9 No hablo fiándome a ciegas de los datos de Zeumer, sino de un análisis personal de los avatares de la tradición del Liber iudiciorum que describí en Estudios críticos y literarios de la Lex Visigothorum, Santiago de Compostela, 1990, tesis mec. (prox. publ.).

$10 \mathrm{~V}$. ERv.. 2.3.4 *..censura illius legis .. que continetur in libro sexto, titulo primo, era secunda ubi praecipitur pro quibus..» o ERv. 9.1.9. Praecipio es también formular en el concilio Tol. XI, celebrado en tiempos de Wamba, para remitir a normas canónicas y bíblicas; la unidad de escritura que se observa en las fuentes legales godas en los periodos de los dos monarcas se debe con toda verosimilitud a la existencia de una mano única, la de Julián (cf. ob.cit., n. 9, pp. 496-500).

"Bastaría un 'ahora' («ut nunc praecipitur») para haber establecido una diferencia clara entre los dos planos temporales: el de la aplicación de ese castigo y el de su regulación legal posterior.

12 Porque pasan por alto la cláusula «ut praecipitur» y no se percatan de la contradicción cuis el Iudicium que comento luego, v. BARBERo-VIGIL, La formeción del Feudalismo en la Peninsula Iberica, Barcelona, 1982, 3*. ed. pp. 115 y 150, o PETIT, De negotiis causarum "Anuario de Historia del Derecho Español ", 55 (1985), pp. 182-184. 
(Iudic. 7) .. non ultra nobis est dubitandum ut illos paueamus iuxta legis huius sententiam et in corpore et in rebus temporali puniri censura (..) Ob hoc secundum latae legis edita hoc omnes communi definiuimus sententia, ut idem perfidus Paulus cum iam dictis sociis suis morte turpissima condemnati interirent, qualiter casum perpetuae perditionis uidentur excipere, qui et euersionem meditati sunt patriae et principis interitum conati sunt eximere. Quodsi forsam eis a principe condonata fuerit uita non aliter quam euulsis luminibus reseruentur ut uiuant ${ }^{13}$.

De hecho el dossier sobre traición redactado en los tiempos de Chindasvindo (formado por 2.1.6 y un extenso canon del concilio VII de Toledo) está presente como fuente de inspiración, a veces simplemente literaria ${ }^{14}$, a lo largo de todo el Iudicium, un apego que contrasta con el abandono del contenido jurídico de esa legislación en la Historia; indicio a su vez de que esa legislación es la única a mano cuando se elabora el primer documento.

Pero el cambio de perspectiva de Julián entre la redacción de uno y otro texto es más profundo de lo que ese trueque de castigo corporal sugiere. La consecuencia política más importante de la actuación de Wamba tras los sucesos de Narbona fue la infamatio, esto es la degradación con pérdida de status y propiedades de buena parte de la nobleza. Este sí es un dato de la realidad. A los dos meses de la expedición, y debido a lo que en ella había sucedido, el rey promulgó un decreto (=Liber Iudic. 9.2.8) sobre cooperación militar donde amenaza con esa purga, y aunque la ley lo plantee en futuro, su aplicación efectiva en los que colaboraron con el usurpador, o no se enfrentaron activamente a él, la confirma Ervigio al lamentarse de las secuelas que había dejado aquella "saeua praeceptio»" ${ }^{15}$. El Iudicium -conforme con 9.2.8- insiste en la legalidad de castigar a los rebeldes «in corpore et in rebus", y por eso recoge también de 2.1.6 las cláusulas que autorizan a la confiscación de sus bienes

Res tamen omnes eiusdem Pauli sociorumque eius in potestate gloriosi nostri domni persistendas esse decernimus, qualiter quicquid de his

${ }^{13}$ Desde «Quod si..* a "uiuant» (y el fragmento sucesivo, que trascribo más abajo) es una transcripción literal (sólo con cambios sinonímicos) de Liber 2.1.6 CHIND. (v. ZEUMER, pp. 55-56, col.1).

${ }^{14}$ Por ejem. Iudicium 3 «compulsi sumus arma arripere... y -en igual contexto- 2.1.6 CHIND. «..arma sumere sepe conpellimur»; Iudic. 6 «.. spontanea promissione in electione .. Wambani regis .. consenserunt» y Toledo VII, VIVES, p. 251 «constante principe cui fidem seruare promiserant in alterius electione.. consentiantw.

is V. Toledo XII (tomo) Vrves, p. 387 y canon 7 p. 394-395. 
agere uel iudicare elegerit serenitatis suae clementia, potestas illi indubitata permaneat, ut seditiosorum nomen funditus a terra dispereat..

(fragmento de Iudic.7 que sigue al trascrito más arriba); en una anticipación retórica de esa sentencia, la arenga del documento justifica en paralelo la infamatio y la ceguera de los perfidi con estos desiderata:

(Iudicium 1) .. Reportent nomen proditionis in posteros, quos indulgentia principalis fecit esse ingratos. Renotentur inter cuneos perfidorum qui genti suae parauerunt excidium, ut reportent in progenies seculorum titulos infamiae suae qui euersores facti sunt patriae; quibus ex clementia princeps dederit uiuere, effossionem luminum non euadant..

En la Historia, por el contrario, desaparece toda mención de despojo e infamatio, probablemente la carga doctrinal en la frase con que recogía la sentencia («decaluationis tantum, ut praecipitur, sustinuere uindictam») está situada en el «tantum»; pero hay todavía datos más explícitos que ese silencio: en la Insultatio, la pieza que complementa la Historia, la misericordia real se hace extensiva expresamente a este punto de la degradación nobiliaria:

(Insult. 6) ..Sed nolo hunc (sc. Wamba) diu super te inclementiorem fuisse causeris cuius tam citatis beneficiis reuestiris. Quum enim iusta tibi seruitus pro merito deberetur, ut uere sanum caput languenti membro compatiens, redactae tibi in seruitutem libertatis hostiam donans et ueteres perfidiae tuae notas clementiori manu obliterans, ante te elegit suae sociam dignitati quam tu paenitendo ablueres maculas quas fecisti, scilicet ut, quia impia temeritate libertatis perdideras titulum, testimonium reciperes gloriosum

Son palabras escritas con idéntico espíritu (y «morfología», cf. «reuestiri» -v.n.20-, «libertatis perdideras titulum» / T.XII «titulum dignitatis amiserant», «testimonium reciperes gloriosum»/T.XII «reuestiri generositatis testimonio».. ${ }^{16}$ ) a las que se ponen en boca de Ervigio en Toledo XII

16 La pérdida de status, de derechos sociales, se identifica en los textos visigodos de este tiempo con la incapacidad procesal-testifical, de ahí el lenguaje empleado en los lugares cit. de T. XII en n. 15, de ahí también las junturas sintéticas que son creación de Julián y utiliza en la Insultatio, Tol. XII o Tol.XIII ensamblando con genitivos de identidad la capacidad testifical y la «libertas», «dignitas» «generositas».., o sea la condición nobiliaria (v.gr. "generositatis testimonio»), o haciendo alternar en frases sinonimas términos de los dos campos semánticos (v.gr. «libertatis titulum = testimonium gloriosum»), ambos ejemplos sacados respectivamente de los pasajes de T.XII e Insultatio que se transcriben arriba. 
cuando se ocupa de la rehabilitación de los poderosos víctimas de las medidas de Wamba

(v.gr. T.XII p.383) ..Unde licet eandem legem (i.e. 9.2.8) nostrae gloriae mansuetudo temperare disponat, uestrae tamen paternitatis sententia hos qui per illam titulum dignitatis amiserant, reuestiri iterum claro pristinae generositatis testimonio deuotissime obtat..

El asunto era tan prioritario que, para otorgar este perdón, Ervigio suprimirá en las leyes civiles la cláusula de Chindasvindo (Liber Iudic. 6.1.7 $)^{17}$ que le impedía al rey en solitario amnistiar a los traidores, y Toledo XII c. 3 dará cobertura a esa supresión ${ }^{18}$. El tema sigue en primer plano todavía tres años y medio después, y el concilio T. XIII (noviembre del 683) lleva las medidas de gracia más lejos: a la devolución de status, la única por la que se atrevía a abogar explícitamente Julián en Insultatio y Toledo XII ${ }^{19}$, añade la de los bienes confiscados («quia incassum a seruitute exuitur qui spoliis premitur») siempre que todavía permanecieran en poder del fisco ${ }^{20}$, y extiende la inmunidad a los descendientes de los traidores (a los que el ludicium implicaba en sus amenazas, cf. Iudic. 1 supra). Este nuevo viraje en el discurso puede hacer del a. 683 el ante quem en la escritura de la monografía histórica.

Aun prescindiendo de este último dato, una conclusión firme de todo lo anterior es que Iudicium e Historia-Insultatio han sido escritos con puntos de vista diferentes frente a un mismo problema, y esto sólo tiene sentido si ha mediado en su redacción el tiempo suficiente para que Julián no sólo cambiase de percepción, sino también estuviese en condiciones o considerase necesario expresar su nuevo punto de vista. Este nuevo enfoque se opone, segun vimos, al decreto de Wamba del a. 673 (i.e. Liber 9.2.8) del que el monarca - vista la situación con que se encuentra Ervigio al subir al tronono se descabalgó en todo su reinado, y es, por el contrario, el mismo que p. 621).

${ }^{17}$ No refleja Zeumer en su ed. del Liber esta supresión (sobre ella escribí en ob.cit. n. 9,

${ }^{18}$ V. ob.cit. n. 9, p. 620-621.

19 Implícitamente sí lo hacía en la Historia al restringir a una pena corporal el castigo y silenciar las confiscaciones.

${ }^{20} \mathrm{~V}$. Tomo (VIVES, p. 412) «rebus quibus fas fuerit deuouimus reuestire» -de nuevo el verbo "revestire», que fuera de éste y los otros dos pasajes citados antes, sólo reaparece en leyes de Ervigio-, y canon 1 ( (De reddito testimonio dignitatis eorum quos profanatio infidelitatis cum Paulo traxit in societatem tyrannidis») que después de repetir la condonación de T.XII e Insult. añade "et quia incassum a seruitute exuitur qui spoliis premitur, hoc etiam adiciendum principis nostri clementia iussit ut ... quum recepto testimonio dignitatis congruis alerentur substantiis.. etc.» 
mantuvieron -al menos sobre el papel- Julián-Ervigio entre los a.681-683. La remisión a una ley ervigiana en la Historia, en contraste con el pasaje de Chindasvindo copiado en el Iudicium, confirma que esos datos pueden traducirse en una nueva data para el relato extenso, y convertir al Iudicium en la versión primera que dio Julián de los hechos, la coetánea al episodio histórico.

Pues ese texto, por más que tenga, de acuerdo con su epígrafe, una estructura diplomática que no llegan a ocultar los vuelos retóricos, es una verdadera pieza historiográfica con el mismo argumento base que la monografía ${ }^{21}$. Sus divergencias están, como se ha visto, en la orientación de la propaganda, pero además hay entre uno y otro escrito elecciones distintas en el léxico que pueden reinterpretarse en función de esa distancia cronológica que postulo.

La más significativa concierne a la titulatura regia; todos los títulos de cuño imperial con que venía revistiéndose la monarquía visigoda quedan reducidos en la Historia al epíteto religiosus (en la juntura princeps religiosus), mientras el Iudicium emplea designaciones tradicionales y sobre todo este combinado: gloriosus domnus noster, título inequívocamente referido a un Wamba entronizado, no sólo por el posesivo noster, pues gloriosus sólo era aplicable entre los visigodos al monarca reinante; como en el Iudicium, y sólo con el cambio a primera persona, Wamba es en su ley militar nostra gloria.

Teillet justifica los contrastes de vocabulario entre Historia y Iudicium por la distancia que media entre una obra elaborada con un sentido en gran medida religioso y lo que ella define como un documento «oficial de carácter estrictamente narrativo y jurídico" ${ }^{22}$; pero desde la perspectiva abierta arriba, cabe otra opción y es que Wamba, cuando se redactó la Historia, no podía apellidarse gloriosus ni ser apostrofado (aunque fuese indirectamente) con un domnus noster sencillamente porque ya no reinaba. Es cierto que religiosus es un calificativo característico de este rey, el sínodo celebrado en Toledo bajo su mandato (Toledo $\mathrm{XI}$ ) se lo aplica varias veces (pero sin excluir gloriosus y alguna otra titulatura). Su función en uno y otro lugar es recordar una «novedad», el carácter que la unción regia ha imprimido en el monarca, pues, sin entrar en la polémica sobre cuándo se inauguró el ritual

${ }^{21}$ Cf. TeILlet (cit. n.1), p. 603: estoy conforme con ella en que el Iudicium ha servido de trama a la Historia.

22 Op. cit. n.1, pp. 603-604. Un indicio de que las diferencias de vocabulario entre uno y otro texto no se deben a la naturaleza del escrito es que las actas de T. XII -documento ciertamente oficial y jurídico- retoman sin cortapisas el vocabulario de la Historia, incluidos términos de los que Teillet comenta (loc. cit.) por su contraste con el Iudicium, pero esas actas no restringen la titulatura del monarca. 
de la unción, no hay duda que es a finales del s. VII cuando da pie a una teorización (la Historia Wambae es el principal exponente) sobre los deberes de la monarquía, integrándose en una estrategia más amplia que reviste litúrgicamente diversas actividades del rey. Ceremonias para despedirle cuando sale en campaña, o para recibirle cuando vuelve a Toledo -recogidas en el Liber Ordinum - fueron creadas por la misma época; y uno de los muchos indicios que señala hacia el Reinado de Wamba o su sucesor inmediato es que el monarca de esos ritos es un rex sacratus y por eso también un princeps religiosus; sin embargo esto no impide vincular el título al monarca actual por medio de un noster ${ }^{23}$. Que ninguna de las trece apariciones del "princeps religiosus» vaya en la Historia acompañada del posesivo es tanto más chocante porque el autor se refiere constantemente a los hombres del rey como nostri o nostrorum exercitus. Y no podrá alegarse que la liturgia es un contexto menos sagrado o donde la figura del rey precisa menos ser nimbada de un hieratismo distanciador.

Otra señal de que Wamba fue en la Historia conscientemente desmarcado del papel de gobernante en activo, por tanto de todo título expresivo de ese gobierno: desde que la unción se incorporó a la elección real legíti$\mathrm{ma}^{24}$, el registro oficial de los reyes visigodos -la llamada Chronica Regum Visigothorum adjunta al Código civil-divide el contenido de las entradas en dos fechas, la que indica la designación por el predecesor u otras personas, y la que corresponde al día de la unctio. En un momento de la narración alude Julián a la primera de esas datas, empleando el tipo de fórmula acuñada en la Cronica para esa transferencia laica del poder

Hist Wam. 20 ..miro occultoque dei iudicio id agente ut eodem die perceptum tyrannus regnum deponeret quo religiosus princeps regnandi sceptrum a Domino percepisset ${ }^{23}$. Erat enim dies illa kalendarum septembrium

Quiere esto decir que Julián llama «religiosus» a Wamba incluso en un contexto donde de algún modo resulta impropio: no sólo está recordan-

${ }^{23}$ V. Liber Ordinum ed. Ferotin, p. 150 «sublimitas regum..: esto presenti religioso principi nostro illi..»; v. también el apóstrofe directo en p. 154 «Signum salutaris claui et ligni quod deuotis manibus, sacrate princeps, suscepisti, sit tibi ad tutelam..»

${ }^{24} \mathrm{O}$ por lo menos desde que se consideró un elemento a reseñar, esto es desde Wamba; este indicio de la Crónica es sólo uno de los muchos que apuntan hacia Wamba como primer protagonista del rito, contra quienes defienden su implantación anterior.

${ }^{25}$ Salvo este precedente ¿cronológico?, es en los textos de época de Ervigio, y en los de su sucesor Egica -tal vez porque ninguno de los dos podía sustentar su elección en un consenso de la nobleza-, donde se emplea el mismo lenguaje y se mezcla conscientemente la elección humana y divina del monarca. 
do una fecha, el 1 de Septiembre, en que aún no ha sido consagrado, sino que además está haciéndose eco de una fórmula en la que el rey aparecía siempre con sus títulos institucionales. Hay de hecho en la Cronica una entrada -justamente la de Ervigio- que sólo difiere de la inserta en el relato por la titulatura ${ }^{26}$

Suscepit autem succedente die II feria gloriosus dominus noster Eruigius regni sceptra quod fuit idus Octobris..

Hasta aquí lo que han dado de sí las desavenencias entre el Iudicium y la monografía. Los demás pasajes cuya carga ideológica interesa ya no tienen correlato en el primer texto; se han intercalado entre los sucesos bélicos de Narbona con fines demostrativos; las enseñanzas que proponen los desvinculan de hecho de la crisis inicial del reinado de Wamba para encajar, a veces literalmente, con las pretensiones que Julián sacó a la luz en Toledo XII, nada más salir de escena aquel monarca, y que resultan bien extrañas en un joven clérigo simplemente afanoso de agradar al rey. Es sabido que en ese concilio (y el siguiente, Tol. XIII) se recopilan textos y se dictan normas tendentes a demostrar y hacer efectiva la primacia de la sede metropolitana de Toledo, tanto sobre su propia provincia eclesiástica, como sobre las demás sedes hispanas. El dispositivo más elocuente, en cuanto a la segunda pretensión, es el del canon 6 de Tol. XII donde se establece que, a partir de ese momento, todas las consagraciones obispales se realizarán en la urbs regia y los candidatos serán elegidos por el rey y el metropolitano de Toledo. El mismo tema -elección y ordenación de episcopi- ronda la mente de Julián cuando redacta la Historia; el capítulo 6, utilizando como pretexto la forma en que ocuparon los rebeldes la cátedra de Nimes, instruye acerca de cómo no llevar a cabo uno de esos nombramientos:

Dein in sublati pontificis locum perfidiae suae socium Ranimirum abbatem inducit episcopum. In cuius praelectione nullus ordo adtenditur, nulla principis uel metropolitani definitio prestolatur, sed erecto quodam mentis superbae fastigio, contra interdicta maiorum ab externae gentis duobus tantum episcopis ordinatur

${ }^{26}$ La entrada de Wamba emplea «suscepit.. regni gubernacula..». Sobre este tipo de fórmula $v$. ob.cit., n.9, pp. 721-722. 
Hay paralelismos verbales con el texto conciliar muy claros ${ }^{27}$, y al emparejar rey y metropolita, también el contenido orienta hacia la prescripción (¿posterior?) del sínodo; pero si en la Historia se piensa, no en el pontífice de Toledo, sino en el metropolitano al que Nimes está subordina$\mathrm{da}^{28}$, la «lección" sigue siendo válida contra imposiciones unilaterales de obispos por parte de los reyes al margen de los primados. Esta situación estuvo de hecho presente en la asamblea del 681; antes de la norma general mencionada, las actas recogen la anulación de sedes que Wamba había creado por propia iniciativa, y la destitución de sus titulares -cuya ordenación corrió a cargo de unos obispos coaccionados por el príncipe-; entre los destituidos está el competidor que «con su habitual tozudez» (solitis obstinationibus) Wamba le había instalado a Julián -es evidente que sin el consentimiento del primado- a las propias puertas de Toledo, en la Iglesia pretoriense de S.Pedro y S. Pablo.

Ese era el templo destinado a los rituales monárquicos por lo que no resulta una ubicación accidental, ya que el control sobre ellos, sobre el rey en última instancia, era sin duda vital para las pretensiones del metropolita; las medidas centralistas del periodo Julián-Ervigio tienen siempre a ambos como protagonistas, se sustentan en la doble condición de Toledo como "prima sedis» y como «urbs regia». Hay un antecedente visigodo, en Mérida el a. 666, que resulta instructivo de cómo se encadenaban de forma natural las aspiraciones de una sede a centralizar su dominio (en este caso diocesano), el afán por vincular con el rey dicha sede y el desarrollo en la misma de una liturgia regia ${ }^{29}$. Y si en la Historia apuntaba discretamente el primer aspecto (v. arriba), los otros dos, como obra centrada en el príncipe, se exponen con parsimonia.

${ }^{27}$ Cf. Tol. XII, c.6 «libera principis electio praestolari» con la $3^{2}$ y $4^{2}$ líneas del pasaje de la $H$ ist. copiado arriba.

${ }^{28}$ De hecho el canon de Tol. XII también dejaba este margen «saluo priuilegio uniuscuiusque prouinciae licitum maneat deinceps Toletano pontifici..» y mantenía para el metropolita provincial el derecho de supervisión e instrucción del nuevo obispo. Julián ha querido en otro lugar de la Historia realzar la jerarquía de ese cargo eclesiástico, cf. infra y n.45. Sería difícil un control a nivel nacional si no se contaba como paso previo con una organización provincial centralizada.

${ }^{29}$ Los cánones del sínodo del año 666 se dedican en su mayor parte a los esfuerzos centralizadores de la sede emeritense; su afán por vincular al monarca con la ciudad se refleja en la declaración inicial ( $\star .$. in Emeritensi urbe quod caput huius prouinciae noscitur esse et sub principali nomine manet dedicataw), y en su apelar reiteradamente a la autoridad conjunta del príncipe y el metropolitano; como complemento a las normas de control eclesiástico, el concilio legisló sobre la celebración de misas específicas durante las campañas bélicas de la hueste real, desde la salida de la expedición hasta su regreso, preludiando los ritos más tarde organizados en Toledo en esas mismas ocasiones. 
Ya se ha escrito ${ }^{30}$ que una de las funciones de la obra es hacer publicidad del rito monárquico más importante, aquel que legitima en su cargo al rey $^{31}$-la unctio-, pero esa publicidad se orienta -según ha puesto de relieve Collins $^{32}$ - a subrayar el monopolio de la Iglesia de Toledo sobre dicha ceremonia. El texto es muy explícito

tamen dilato unctionis tempore usque in nono decimo die, ne citra locum sedis antiquae sacraretur in principe (c.3)

y poco después con una retractatio de la misma idea

Nam eundem uirum quamquam diuinitus abinceps et per hanelantia pleuium uota et per eorum obsequentia regali cultu iam circumdederant magna officia, ungi se tamen per sacerdotis manus ante non passus est quam sedem adiret regiae urbis atque solium peteret paternae antiquitatis, in qua sibi opportunum esset et sacrae unctionis uexilla suscipere et...

Es decir, importa el lugar de la consagración -sedis antiqua, solium paternae antiquitatis, nombres enaltecedores de Toledo, inspirados en la Constantinopla de Corippo ${ }^{33}$-, tanto o más que la consagración misma (por eso Julián contrapuso a un gobernante legítimo ungido en Toledo, no un tyrannus sin chrisma, sino alguien que se ha procurado esa y demás distinciones reales muy lejos del centro político-religioso $)^{34}$. Es significativo que las rivalidades entre metropolitanos se centraran a menudo -aunque el testimonio directo es de épocas posteriores- en el derecho a realizar unciones reales $^{35}$

30 TeسLT, art.cit., n.5, p. 422.

${ }^{31}$ No es Wamba, sino Ervigio el primer y único rey que contará sus años de reinado por la fecha de la unción, y aunque no se puede decir en sentido estricto que la Historia sea en este punto incoherente con la forma de datar de Wamba, ya que deja clara su condicion de rey tras su aclamación por los Grandes, antes de ser ungido, es fácil deducir que es Ervigio el que se adecúa más a los ideales del narrador.

32 Art.cit. n. 2, p. 45.

${ }^{33}$ Recojo este y otros ecos de Corippo en las obras de Julián en ob.cit. n.9, p. 726, n. 24.

34 La única aparición del usurpador como *unctus» es en la cabecera de una epístola que supuestamente envi6 a Wambe («In nomine Domini Flauius Paulus unctus rex orientalis Wambani regi austro»), pero que sin duda inventó Julián con fines burlescos; los títulos «rex orientalis»/»r.austro» son, a mi entender, evocación irónica de las estructuras políticas francas, lo que ya en sí descalifica cualquier pretensión de Paulo sobre Hispania cuya unidad y extensión han sido realzadas en la Historia.

35 Para este dato Nelson, ob.cit., n. 36, p. 243 n. 3. 
En un análisis de los denominadores comunes que rodearon el establecimiento de esa ceremonia en cuatro enclaves distintos (el visigodo entre ellos) Nelson ${ }^{36}$-que sin embargo no tuvo en cuenta la Hist. Wambor- llega a conclusiones que integran bien algunos de los puntos examinados hasta aquí y pueden servir de marco a los que siguen: en todos esos ámbitos el ceremonial llegó acompañado de una actividad sinodal y una reflexión sobre el poder de los reyes; los ideólogos de la Iglesia pusieron ese acto litúrgico al servicio de una idea, crear un lazo de dependencia en el rey-ordenado respecto a sus ordenadores para influir sobre el ejercicio de su autoridad, y comprometerle como brazo ejecutor de la disciplina eclesiástica ${ }^{37}$. Julián plasma ese ideal en la Historia, pero una vez más las directrices concretas que Wamba aparece poniendo en práctica son las que Ervigio suscribió en sus leyes, después de haber encomendado él mismo su elaboración a los Padres reunidos en Toledo XII.

Un primer caso: en el cap.10, destinado a mostrar a la realeza que es su propio interés el que está en juego cuando no se responsabiliza de las almas de sus súbditos, Julián dibuja a Wamba reprimiendo los desórdenes sexuales (los adulteria en el sentido amplio, medieval del término) de los soldados durante la expedición bélica

Sed quia insolens quorundam e nostris motio .. cum incensione domorum adulterii facinus perpetrabat, tanto disciplinae uigore iam dictus princeps in his et talibus patratum uindicabat scelus, ut grauiora in his supplicia illum putares impendere, quam si hostiliter contra illum egissent. Testantur hoc praecisa quorundam adulterorum praeputia, quibus pro fornicatione hanc ultionis inrogabat iacturam. Dicebat (..) «Nam ego si ista non uindico, iam ligatus hinc uado (..), iusto Dei iudicio capiar, si iniquitatem populi uidens ipse non puniam..

Ervigio hace gala del mismo celo revisando a fondo las leyes anteriores referentes a la moralidad sexual y matrimonial ${ }^{38}$, pero además sus reformas

36 Janet L. NeLson, «National Synods, Kingship and Royal Anointıng» ahora incluido en su Politics and Ritual in Early Medieval Europe, Londres 1986 v.p.243 ss.; es también instructivo el trabajo «Kingship, law and liturgy in the political thought of Hincmar of Rheims*, ibid. p.133 ss. 51,4 .

${ }^{37}$ Este ideal, todavía desvinculado de la unción, ya lo expresaba Isidoro, Senten., III,

38 En el caso del divorcio, su reforma va de la mano con lo que en $\mathrm{T}$. XII prescribieron los Padres dirigidos por Julián: la modificación de la ley del divorcio (3.6.2) no aparece en Zeumer atribuida a Ervigio: justifico su autoría, así como la iniciativa directa de Julián en el tema, en ob. cit., n. 9, p. 619. 
se basan en concepciones jurídicas paralelas a las que idealiza la Historia. Pues si en ella, esos praecisa praeputia quieren mostrar la dureza de Wamba con este tipo de deslices ${ }^{39}$, el código de Ervigio (en contra de los principios que mantuvo Recesvindo en su Liber) admite como medida disciplinar necesaria la mutilación ${ }^{40}$, y ésta es especialmente recomendada con los mismos que provocaron las iras de Wamba durante la campaña, los adulteri ${ }^{41}$.

Otro ejemplo es la obsesión por la cuestión hebrea: Julián la inculcó, o por lo menos compartió con Ervigio; no sólo una de sus obras sobre el tema (el De comprobatione sextae aetatis) se presenta como escrita a instancias del rey, sino que los preceptos judíos del monarca -su legislación más tempranaponen especial énfasis en una prohibición -que los judíos no tengan a su servicio esclavos cristianos- cuya defensa asumía un tratado de Julián que no se ha conservado ${ }^{42}$; este antisemitismo es compartido por el Wamba de la Historia ${ }^{43}$, pero difícilmente por el Wamba histórico que, a diferencia de otros monarcas, no dejó una sola norma o hizo alusión a tal problemática.

Pero de todas las nouellae o reformas de Ervigio, es el decreto militar el que tiene, por su temática, una relación más específica con la monografía; también aquí, como era previsible, trasluce el punto de vista eclesiástico. Junto a la solicitud a los obispos de Tol. XII de que reintegrasen a su condición a los nobles degradados por Wamba, el rey declaró en ese sínodo su intención de temperare el edicto en el que aquel se había amparado (v. Tol.XII p. 383); pero en la realidad, la nueva ley militar (Liber 9.2.9) sólo dulcifica la del antecesor en un punto, y es que suprime (por medio del silencio) la obligación del clero de aportar sus personas y recursos a la hueste que fuera convocada en ayuda del rey, y por tanto los castigos que Wamba había previsto para las distintas jerarquías eclesiásticas.

Este silencio hace juego con el de la Historia; de ser ésta un colofón de lo ocurrido en Narbona el 673 -más aún de ser, como se pretende, un encargo de la corte donde quedaron plasmadas las ideas del rey protagonista $^{44}$ - a Wamba le habría gustado ver cómo en ella se incitaba al concurso de

39 Y también su forma «ejemplarizante» de aplicar el castigo -sólo «algunos» culpables son castrados-, lo que recuerda asimismo el carácter disuasor de algunos castigos incluidos por Ervigio en las leyes, Ob. cit., n.9, p. 63, n. 83 y p. 492.

40 Ob.cit. n. 9, p. 589. Sobre la repugnancia del legislador anterior-Recesvindo- hacia las truncationes, ibid. p. 588.

${ }^{41}$ Liber, 3.4.13 (ZeUMeR, p. 154, col.2).

42 «..librum responsionum .. in defensionem canonum et legum quibus prohibentur Christiana mancipia dominis infidelibus inseruire» (PL.96, col. 448); sobre lo primordial de esta cuestión en todo el dossier judío de las leyes de Ervigio, ob.cit., n. 9, p. 544 y n. 51 .

43 V. Hist. cap. 5 , cap. 28 e Insultatio 2.

44 Así lo creen por ejemplo Dietrich Claude, Adel, Kirche und Königtum im Westgotenreich, Sigmaringen, 1971, p.154 o TeILlET, ob.cit., n.1, p. 600 y art.cit., n. 5, p. 
los religiosos en la guerra, puesto que ésta fue una de las obsesiones con que regresó de la campaña. Pero Julián no ilustró con ejemplo alguno esa pretensión; al contrario, el modelo del trato rey-obispos que plantea está marcado por la consideración especial que el primero debe a los segundos, según refleja el diálogo de los cap. 21-22 entre Wamba y el metropolitano de la provincia gala, Argebado ${ }^{45}$. De forma lateral, a través del repudio del narrador por el tratamiento físico y el "exilio" que recibió de los rebeldes el obispo de Nimes (cap.6), se condena la imposición de penas de esa naturaleza -y la ley militar de Wamba las imponía-al clero.

Los indicios de fondo que vinculan la Historia Wambae con los primeros escritos de época ervigiana tienen un correlato formal. Entre la pieza histórica sobre Wamba y las fuentes redactadas con certeza durante su reinado (tres Edictos del Liber Iudiciorum y las actas de Toledo XI) se hallarán fácilmente similitudes compositivas; pero esto, como ya indiqué (n.10), se debe a que Julián debió asumir muy pronto la tarea de redactor monárquico; prueba de ello es no sólo la existencia del Iudicium que ampara las resoluciones que el rey toma nada más regresar de la Narbonense, sino la misma ley 9.2.8 donde se plasmaron oficialmente esas resoluciones y que tiene muchos síntomas de autoría julianea ${ }^{46}$.

Sin embargo, las repeticiones de junturas (a veces en contextos muy diferentes) y de vocablos exóticos o comunes son mucho más frecuentes entre la Historia y las actas de Toledo XII o las leyes de Ervigio, que con los escritos jurídicos del antecesor: la impresión, también desde este punto de vista, es que todo ese dossier (Historia, T. XII, Liber ervigiano) ha salido de la pluma del metropolitano y con poco intervalo de tiempo.

45 Argebado acude ante Wamba a solicitar el perdón, y la misericordia del rey condona las vidas de los perfidi -i.e.se nos muestra a un monarca atendiendo a la doctrina de la «compassio» que le recuerda un primado-, pero sólo al propio Argebado -después de que «inlacrimans sublevari episcopum a terra precepit»- le otorga la exculpación absoluta. Las apariciones de este personaje son de las que parecen más claramente un «injerto» con fines «demostrativos» (cf. el papel contradictorio del personaje en los cap. 7 y 21), y curiosamente no aparece en el Iudicium, a pesar de que en la enumeración de sediciosos este doc. es más completo que la Historia.

46 V. Ob.cit.n.9 p.498-9. Quienes imaginan que la Historia fue la «revelación» de Julián en la corte, olvidan las palabras de su biógrafo Félix, «Post decessoris sui obitum diuinae $m$. Ildefonsi, a decimo septimo ferme anno Recesuinthi principis (i.e. a.666), necnon et per omne Wambanis imperii tempus usque ad tertium regni gloriosissimi Egicanis regis annum, in leuitici, presbyterii ac pontificatus honore consistens, celebre nomen obtinuit» (P.L. 96, cols. 446-447) 
No desarrollo, por ahora, esta vía de análisis lingüístico, pero sólo con lo dicho creo fundamentada la hipótesis de situar la escritura de la obra de Julián no antes del 681 y probablemente no después del $682^{47}$; es el único momento en el que encajan todos los elementos descritos. Puesto que entonces Wamba acaba de retirarse o ser retirado del poder, esta data arrastra consigo un replanteamiento drástico de los móviles globales de Julián cuando elige aquel episodio de su reinado como telón de fondo de su speculum principis.

La versión ¿legendaria? de la deposición del viejo príncipe en una intriga cuyos hilos manejaron Julián y Ervigio, da pie a imaginar intenciones bastante retorcidas en esa elección del primado: iredacta esta obra para despejar las dudas sobre el origen de la enfermedad de Wamba, cultivando el mismo la gloria del ahora penitente? -la cantidad de documentos exhibidos ante la asamblea de Tol.XII que habría suscrito Wamba en su lecho de muerte, dando legalidad al traspaso de poder a Ervigio, indica que las explicaciones fueron necesarias-, o incluso, ¿pretende Julián justificar de forma implícita la propia deposición dejando ver con su relato lo lejos que estaba la conducta del Wamba real de lo que era preceptivo en un rey consagrado?.

Quizás sea imaginar demasiado, pero Teillet ${ }^{48}$ ya había visto que una parte del esquema de la narración sigue las líneas argumentales del relato sobre Saul en el libro I de los Reyes, y que la misma historia bíblica se prolongaba fuera de la monografía con la promulgación de esa ley draconiana de Wamba (9.2.8) para la leva militar, e incluso -proponía la autora- con la deposición del rey y la unción de un nuevo monarca; pero, para ella, ésto sólo habría ocurrido mucho después, cuando los «descarríos» de Wamba completaron su asimilación a Saul y permitieron que Julián -sintiéndose un nuevo Samuel- contribuyera sin escrúpulos a retirarle del poder ${ }^{49}$. En tal caso ¿no resulta más verosímil que Julián meditara el paralelismo de ambas historias al completo, y no que la realidad acabara, ocho años más tarde, por redondear su imitación literaria? Sobre todo porque, de no ser así, Julián habría intuido mucho más que el destronamiento (al fin y al

47 No se puede excluir totalmente una data posterior, pero resulta poco verosímil, tanto por el nuevo cambio de actitud respecto a la nobleza degradada por Wamba que, según indiqué más arriba, se produce en Toledo XIII, como por el total paralelismo de la Historia con Tol. XII en ese mismo tema (y en otros).

48 Ob.cit., n.5, pp. 418-419.

49 Los ideólogos de la unción -como Hincmaro de Reims- comprendieron que el compromiso que el rey contraía con ella (y con las professiones monárquicas que acompañan su ascensión precisamente desde la misma época en que se testimonia el rito y en el mismo ámbito, el visigodo) también abría el camino para, llegado el caso, poder deshacerse de un rey indigno, cf. NeLSON, ob.cit., n. 36, p. 252. 
cabo esto es sólo una suposición nuestra) sino los tropiezos concretos del protagonista que ¿con el tiempo? iban a justificar que fuese apartado del tronoso.

Pero dejando de lado estas especulaciones que surgen a los márgenes de la obra, lo que el contenido de ésta autoriza a afirmar es el interés del autor por dar cobertura a la política -convertida en seguida en legislación canónica y civil-que acompaña el ascenso de Ervigio y, en concreto, justificación a lo que es prioridad y obsesión de este nuevo reinado: reintegrar a su condición a los nobles víctimas de la represión de $\mathrm{Wamba}^{51}$ y prevenir situaciones similares en el futuro. El refuerzo debía ser muy necesario puesto que incluso los sectores eclesiásticos se oponían a aceptar el perdón de los adversarios de Wamba -lo leemos en el canon 3 de Tol. XII, y puede deducirse de la escasa asistencia a esa misma asamblea-. Cuando en Tol. XIII se vuelva sobre el mismo asunto y se logren muchas más subscripciones, Ervigio habrá cedido importantes prerrogativas a los estamentos nobiliarios para conseguirlo.

El problema no era nuevo; con mayor o menor gravedad, con unas connotaciones u otras, se producía casi en cada advenimiento de un soberano visigodo; la necesidad de asegurar la fidelidad y recursos bélicos de los propios partidarios, forzaba al despojo de los enriquecidos con igual fin por el predecesor $^{52}$. Muchas veces los eclesiásticos tomaron la pluma para cortar esta cadena y dar alguna estabilidad al régimen, ya fuese en una simple carta, solicitando misericordia al rey, como hizo Fructuoso, o en tratados doctrinales al modo de Isidoro, o a través de la legislación canónica (Tol. IV, VIII, XII son los ejemplos más notables).

El procedimiento propagandístico que Julián emplea era relativamente novedoso -ya Isidoro había intercalado en sus obras históricas mensajes docentes destinados a la monarquía - pero en sí mismo resulta poco extraño. Mucha historiografía altomedieval fue compuesta idealizando o manipulando de otros modos el pasado para justificar coyunturas posteriores o

so De no admitirse la revisión de la data, habría que resolver esa paradoja singular (a saber, el que Wamba se dedicara concienzudamente a "desmentir» los ideales que Julián le había hecho representar en su narración), pero también éstas (resumiendo los argumentos anteriores): 1) Julián es sólo un aspirante a la cátedra de Toledo pero se expresa ya con toda la conciencia de quien defiende ese puesto; 2) y más enigmático y problemático, al mismo tiempo que redacta su speculum sermoneando contra las represalias antinobiliarias de los reyes, compone los escritos oficiales (Iudicium, probablemente también la ley 9.2.8) que legalizan las de Wamba.

s1 Nobles que tal vez Wamba había sustituido en cargos importantes por libertos y esclavos no palatinos, cf. Toledo XIII c. VI.

\$2 Algunos de los reyes legisladores intentaron dar una cobertura legal a operaciones de esta naturaleza, cf. ob.cit., n.9, p. 48, n.62 
dar lecciones al presente. Un bello exponente del método es la Historia Eclesiástica de Beda ${ }^{53}$, y sin salir del mundo visigodo, la Vita Desiderii del rey Sisebuto está -según Fontaine $e^{54}$ - destinada a la damnatio memoriae de los dos reyes francos recien fallecidos que la protagonizan, para establecer con su sucesor un nuevo clima de entendimiento. Isidoro, por su parte, ha reescrito sus obras históricas adaptándolas a cambios coyunturales. En cierto modo, podría haber entre el ludicium -redactado en connivencia con las ideas de Wamba y su ley militar-, y la Historia -donde se revisa esa posición-, una relación análoga a la que existe entre las dos versiones de la Historia Gothorum. Recordemos también que tanto Isidoro como Julián compusieron obras teóricas (ya directamente doctrinales, sin la envoltura narrativa) en apoyo o como reflexión sobre medidas legislativas que se adoptaron en su tiempo y por su influjo directo $\$$ ".

\section{RÉSUMÉ}

Les interprétations historiques et littéraires de l' «Historia Wambae» partent toujours du principe que l'oeuvre a été écrite peu après les faits qu'elle relate, autour de 673-4 après J.C. Le seul justificatif de cette date est le composant panégyrique qui est attribué au texte, mais ce qu'il y a de certain c'est que ce composant n'est concrété dans aucune des formes reconnues par la tradition littéraire ancienne. Tout au contraire, des éléments beaucoup plus objectifs qui rattachait la pièce à des mesures juridico-politiques que Julien prétend imposer quand il monte sur le trône en 681, et précisément afin d'éviter les chemins par lesquels s'étaient défait le royaume de Wamba, ont passé inaperçus. Cet enchaînement se vérifie (tant du point de vue formel comme idéologique bien que ce soit ce deuxième point que nous exploiterons en premier lieu): 1) en comparant l'Histoire ave les actes du concile XII de Tolède et avec la législation de Erwigius, 2) en

${ }_{33}$ Según la interpretación, muy convincente, que desarrolla W. GOFFART, The narrators of barbarian history, Princeton Univ., 1988, pp. 235 ss.

34 Political Function of Visigothic Hagiography en «Visigothic Spain», ed. JAMES, Oxford, 1980.

"s Para Isidoro, v. por ejemplo CAzIER, Les Sentences d'Isidore et le IV Concile de Tolede en «Actas..» (cit.n.5) pp. 373-386; de Julián hemos mencionado un tratado que, por su título, debía avalar el contenido de las leyes judías de Ervigio, y concretamente de aquellas que más rechazo social provocaban (v.ob.cit., n.9, p. 544 y n.51); otros escritos perdidos abundan en lo mismo así como cuñas dispersas en sus obras conservadas (por ejemplo, la preocupación por las confiscaciones de bienes a los nobles y su degradación, se injerta en uno de los contrarios del Antikeimenon, el num.120, of. ob.cit. n.9, p. 498, n.56).

- Quiero expresar mi agradecimiento al Prof. M.C.Díaz y Díaz por haber leído la primera versión de estas páginas, y haber contribuido con sus sugerencias a clarificar la exposición. 
analysant les contradictions entre la monographie et les sources qui, en toute sûreté, furent rédigées au fur et à mesure des événements de 673: la loi militaire promulguée par Wamba et le nommé Iudicium, cette même année, un document qui avalise l'esprit de ce décret royal et qui fut rédigé par le propre Julien. Le report de l'oeuvre à l'an 681 (au moins) ouvre à nouveau la question sur les raisons qui conduisirent à sa rédaction -on trouvera quelques suggestions à ce propos-, apporte un nouvel élément de jugement autour des circonstances obscures qui entourèrent la déposition de Wamba, et, en dernier ressort, place l'écrit de Julien dans cette vaste tradition historiogaphique du Haut Moyen-Age qui a utilisé la manipulation du passé pour justifier et faire la propagande du présent.

\section{SUMMARY}

Historic and literary interpretations of the «Historia Wambae» take always for granted that the work was written not long after the events that it narrates, around $\mathbf{6 7 3}$ or $\mathbf{6 7 4}$ after Christ. The only evidence that supports this date is the panegyric component attributed to this text. But, in fact, this component is nowhere to be found in the forms canonised by the antique literary tradition. On the contrary, no mention has been made of much more objective elements that relate this work to juridico-politic measures than Julian wants to impose when he ascends the Erwigius throne in 681 , precisely to avoid the course that the Reign of Wamba had taken. This connection can be checked from both formal and ideological points of view though it is the latter that we will explote mostly: 1) comparing the Story with the certificates of the XII ${ }^{\text {th }}$ Council of Toledo and with Erwigius'legislation. 2) analyzing the contradictions between the monography and the sources that were, with no doubt, redacted during the events of 673: the militar law that Wamba promulgated that very year and the so-called Iudicium, a document that endorses the spirit of this king's decree and that was redacted by Julian himself. The fact of transfering the story to, at least, 681 reopens the question of the motives that guided its redaction -some suggestions about it are proposed-, brings in a new element to take in consideration about the obscure circunstances that surrounded Wamba's dethronement and, as a las point, locates Julian's manuscript in this wide high Middle Ages historiographic tradition that used the manipulation of the past to justify and give importance to present. 